\title{
Renin-angiotensin system gene polymorphisms and endometrial cancer
}

\section{Kirsty G Pringle ${ }^{1,2}$, Sarah J Delforce ${ }^{1,2}$, Yu Wang ${ }^{1,2}$, Katie A Ashton ${ }^{1,2}$, Anthony Proietto ${ }^{3}$, Geoffrey Otton ${ }^{3}$, C Caroline Blackwell ${ }^{1,2}$, Rodney J Scott ${ }^{1,2,4}$ and Eugenie R Lumbers ${ }^{1,2}$}

${ }^{1}$ School of Biomedical Sciences and Pharmacy, University of Newcastle, Callaghan, New South Wales, Australia ${ }^{2}$ Hunter Medical Research Institute, New Lambton, Newcastle, New South Wales, Australia

${ }^{3}$ Hunter Centre for Gynaecological Cancer, John Hunter Hospital, Newcastle, New South Wales, Australia ${ }^{4}$ Division of Molecular Medicine, Pathology North, Newcastle, New South Wales, Australia

\begin{abstract}
Endometrial cancer (EC) is the most common gynaecological malignancy and its incidence is increasing. Dysregulation of the endometrial renin-angiotensin system (RAS) could predispose to EC; therefore, we studied the prevalence of RAS single nucleotide polymorphisms (SNPs) in Australian women with EC. SNPs assessed were AGT M235T (rs699); AGTR1 A1166C (rs5186); ACE A240T and T93C (rs4291, rs4292) and ATP6AP2 (rs2968915). They were identified using TaqMan SNP Genotyping Assays. The $C$ allele of the AGTR1 SNP ( $r 55186$ ) was more prevalent in women with EC (odds ratio (OR) 1.7, 95\% confidence interval (CI) (1.2-2.3), $P=0.002)$. The $C$ genotype of this SNP is associated with upregulation of the angiotensin II type 1 receptor (AGTR1). The $\mathrm{G}$ allele of $A G T$ rs699, which is associated with higher angiotensinogen (AGT) levels, was less prevalent in women with EC (OR 0.54, 95\% Cl (0.39-0.74), $P<0.001)$ compared with controls. AGT and AGT formed by removal of angiotensin I (des(Ang I)AGT) are both anti-angiogenic. In women with EC who had had hormone replacement therapy (HRT), the prevalence of the AGTR1 SNP (rs5186) and the ACE SNPs (rs4291 and rs4292) was greater than in women who had no record of HRT; SNP rs4291 is associated with increased plasma ACE activity. These data suggest there is an interaction between genotype, oestrogen replacement therapy and EC. In conclusion, the prevalence of two SNPs that enhance RAS activity was different in women with EC compared with healthy controls. These genetic factors may interact with obesity and hyperoestrogenism, predisposing ageing, obese women to EC.
\end{abstract}

\section{Correspondence} should be addressed to K G Pringle Email

Kirsty.Pringle@newcastle. edu.au
Endocrine Connections

(2016) 5, 128-135

\section{Introduction}

Endometrial cancer (EC) is the most common gynaecological malignancy and its incidence is increasing. Worldwide, 288,000 women were diagnosed with EC in 2008 (www.wcrf.org/int/cancer-facts-figures/ data-specific-cancers/endometrial-cancer-cancer-liningwomb-statistics), accessed on 30 January 2013), and potential risk factors for this disease include obesity, hypertension, diabetes and hyperoestrogenism, all of which are linked to activation of the renin-angiotensin system (RAS) $(1,2)$.

The RAS is an important circulating endocrine system that controls blood pressure, salt and water balance, http://www.endocrineconnections.org DOI: 10.1530/EC-15-0112 (c) 2016 The authors Published by Bioscientifica Ltd

\author{
Key Words \\ - renin-angiotensin system \\ - single nucleotide \\ polymorphisms \\ - endometrial cancer \\ - angiotensinogen \\ angiotensin II type 1 \\ receptor
}

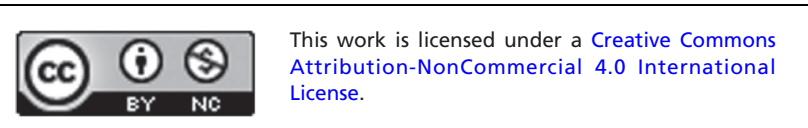


and aldosterone secretion; it plays a major role in the aetiology of hypertension. Renin releases ten amino acids from angiotensinogen (AGT) resulting in the formation of Ang I and a large protein (des(Ang I)AGT). Both AGT and des(Ang I)AGT are non-inhibitory serpins and can inhibit angiogenesis (3).

Angiotensin-converting enzyme (ACE) then removes two amino acids from Ang I to produce Ang II; the major active peptide of the RAS which, via the angiotensin II type 1 receptor (AGTR1), stimulates angiogenesis and cell proliferation $(4,5,6)$. In tissues, inactive prorenin is non-proteolytically activated by binding to the (pro)renin receptor (ATP6AP2), so it forms Ang I and des(Ang I)AGT from AGT. Thus, the prorenin/ATP6AP2 interaction can play a role in activating tissue RASs and influencing angiogenesis. When prorenin binds to the ATP6AP2, it can also activate intracellular signalling (e.g. phosphorylation of MAPK3/MAPK1) and WNT1 signalling pathways (7), which stimulate tumourigenesis.

The endometrium expresses all of the components of the RAS in both glandular cells and in stromal cells, where the levels vary throughout the menstrual cycle (8). Stromal endometrial cells exposed to a 'cocktail' of medroxyprogesterone acetate, $17 \beta$-estradiol and cyclic AMP (cAMP) decidualise and express renin, and secrete prorenin and vascular endothelial growth factor (VEGFA), a potent angiogenic factor (9). The endometrial RAS, like other tissue RASs, has been implicated in angiogenesis, neovascularisation and cell proliferation $(4,5,6)$; all of these are involved in tumour growth and spread. Overexpression of the pro-angiogenic and proliferative Ang II/AGTR1 arm of the RAS has been found in several cancers such as lung, prostate, cervical and breast cancer (10).

Epidemiological evidence also supports the proposal that the RAS is involved in neoplasia. Suppression of the RAS for hypertension treatment reduces cancer risk. The relative risks of cancer incidence and cancer-related death among male and female patients taking ACE inhibitors for the treatment of hypertension were 0.72 (95\% CI 0.55-0.92) and 0.65 (0.44-0.93), respectively, compared with patients taking other anti-hypertensive medication ( $\beta$-blockers). The relative risk of cancer was lowest in women on ACE inhibitors: 0.63 (0.41-0.93) for incident cancer, $0.48(0.23-0.88)$ for fatal cancer and 0.37 (0.12-0.87) for female-specific cancers (11). In men taking captopril (an ACE inhibitor), the relative risk of prostate cancer was reduced to 0.7 (95\% CI 0.41-1.2) (12). Recent animal studies have also demonstrated that telmisartan, an AGTR1 antagonist, significantly reduces tumour growth in a mouse model of EC (5).
Increased expression of Ang II, AGTR1, AGTR2, VEGFA and oestrogen receptor alpha (NR3A1) has been identified in EC tissues (13). In addition, high positive correlations have been identified between the expression of Ang II, AGTR1 and AGTR2 and advancing grade and stage of the tumour (13). Thus, abnormal activation of the endometrial RAS could contribute to the development and progression of EC via the prorenin/ATP6AP2 and Ang II/AGTR1 pathway.

Overactivation of the RAS can often be attributed to single nucleotide polymorphisms (SNPs) in RAS genes. In this study, we measured the prevalence of five polymorphisms in RAS genes in Australian women with EC and in healthy controls. These polymorphisms were $A G T$ (rs699); AGTR1 (rs5186); ACE (rs4291, rs4292) and the (pro)renin receptor (ATP6AP2; rs2968915). The $A G T$, AGTR1 and ACE SNPs are known to be associated with overactivity of the Ang II/AGTR1 pathway.

\section{Materials and methods}

\section{Study population}

Samples were obtained from 184 women with histologically confirmed type 1 endometrioid cancers treated at the Hunter Centre for Gynaecological Cancer, John Hunter Hospital, Newcastle, NSW, Australia, between the years 1992 and 2005. Patients who had additionally been diagnosed with breast cancer were excluded from the study. The control population was 153 healthy female blood donors. Informed written consent was obtained from all participants. Ethics approval was obtained from the Hunter Research Ethics Committee, University of Newcastle (H-050-0605), and the Hunter Area Research Ethics Committee, Hunter New England Health Service, Newcastle, NSW, Australia (05/03/09/3.14).

Data on body mass index (BMI), diabetes, high blood pressure (HBP), age at diagnosis of EC, age at menopause, family cancer history, hormone replacement therapy (HRT), smoking and alcohol use were collected with self-reported questionnaires. Information regarding recurrence, stage, grade and histology of EC was collected from the medical records. Data on ethnicity were not collected; however, local government statistics for the area of Newcastle report that in 2006 the majority of the population ( $>90 \%$ ) were Australian born with European ancestry (predominately English, Irish or Scottish), 2.6\% were Aboriginal or Torres Strait Islander and very few were of Asian, Indian or South African decent (http://profile. id.com.au/newcastle/ancestry). 


\section{DNA isolation and molecular analysis}

Constitutional genomic DNA was isolated from $10 \mathrm{~mL}$ of peripheral blood collected into EDTA blood tubes using the 'salting-out' method (14), as described previously (15). Genotyping of the five polymorphisms, $A G T$ (rs699); AGTR1 (rs5186); ACE (rs4291, rs4292) and ATP6AP2 (rs2968915), was performed on an ABI PRISM 7500 Real-Time PCR System (PE Applied Biosystems, Foster City, CA, USA), using the 5' nuclease assay TaqMan SNP Genotyping Assays (Applied Biosystems) according to the manufacturer's instructions. Endpoint plate read to determine fluorescence values was performed using Sequence Detection System (SDS) software. The genotyping results were confirmed by a secondary observer. Any sample in which a genotype could not be accurately called was discarded from the analysis.

\section{Statistics}

For each polymorphism, Hardy-Weinberg equilibrium (HWE) was calculated using an online calculator (http:// www.had 2 know.com/academics/hardy-weinbergequilibrium-calculator-2-alleles.html). To determine differences in genotype frequencies between the cases and controls, chi-squared $\left(\chi^{2}\right)$ statistics were calculated. Fisher's exact test was used to determine differences in allele frequencies between cases and controls and odds ratios (ORs) and 95\% confidence intervals (CIs) were calculated. Cubic exact solutions were used to determine if two SNPs were in linkage disequilibrium (http://www.oege.org/ software/cubex/) (16). Fisher's exact test was used to see if the distribution of SNPs was different between women who had EC and who had a positive medical history of HRT, hypertension or diabetes and those who did not. SPSS (version 22; IBM) or GraphPad Prism (Prism version 6.0; Graphpad Software, La Jolla, CA, USA) was used for all analyses. Significance was set at $P<0.05$.

\section{Results}

\section{Patient demographics}

Eighty-seven (50.3\%) of the 184 women with EChad grade- 1 EC, 52 (30.1\%) had grade-2 EC and 34 (19.7\%) women had grade-3 EC; no grading was reported for 11 cases. The median age at which cancer was diagnosed was 63 (range: $36-86$ years, $n=181$ ) and the median age at menopause was 50 (range: $35-62$ ). Out of a total of 169 women, $21 \%$ had a BMI within the healthy range $\left(\mathrm{BMI}=18.5-24.9 \mathrm{~kg} / \mathrm{m}^{2}\right)$, (c) 2016 The authors Published by Bioscientifica Ltd
$29 \%$ were overweight $\left(\mathrm{BMI}=25-29.9 \mathrm{~kg} / \mathrm{m}^{2}\right)$ and $50 \%$ were overweight/obese $\left(\mathrm{BMI} \geq 30 \mathrm{~kg} / \mathrm{m}^{2}\right)$. Of the 184 women, 51\% drank alcohol and 26\% smoked; 9\% had a family history of uterine cancer and $24 \%$ had a history of HRT. The prevalence of hypertension and diabetes was 56 and $23 \%$, respectively. Sixty-three percent of hypertensive women were overweight or obese and $97 \%$ of women with type 2 diabetes were overweight or obese.

\section{Genotype distributions}

The distribution of alleles of all five RAS gene polymorphisms did not deviate from HWE in either population. In both populations, the two ACE SNPs rs4291 and rs4292 were in complete linkage disequilibrium (Lewontin's $D^{\prime}$ statistic $=0.905-1.0$ ).

In women with EC, rs4291 (T) and rs5186 (C) alleles appeared to be associated, in that the TT genotype of rs4291 occurred in $35.7 \%$ of women with the CC genotype of rs5186 (Fisher's exact $=10.4, P=0.03$ ). Neither $A C E$ SNP was significantly linked with rs5186 in the control population.

\section{Genotype and allele frequencies among EC cases and controls}

The two ACE polymorphisms (rs4292 and rs4291) as well as the ATP6AP2 polymorphism showed no significant differences in genotype or allele frequency between the cases and the controls (Table 1). Only the genotype and allele frequencies of AGTR1 (rs5186) and AGT (rs699) were significantly different between women with EC and controls.

Women with EC had a higher prevalence of the C allele in rs5186 of the AGTR1 compared with controls (Table 1 ); $15.4 \%$ of women with EC had the CC genotype compared with only $7.8 \%$ of control women. The $\mathrm{C}$ allele was associated with a significantly increased risk of EC (OR: 1.671, Table 1).

Conversely, women with EC had a decreased prevalence of the $\mathrm{G}$ allele of the $A G T$ polymorphism, rs699 (Table 1). Only $12 \%$ of women with EC had the GG genotype compared with $29 \%$ of controls. The G allele was associated with a significant reduction in EC risk (OR: 0.54, Table 1).

In women with EC, there was no relationship between any SNP and cancer grade, BMI, family history of uterine cancer, history of smoking, alcohol, diabetes or HBP (Table 2). The distribution of the genotypes of rs4291, http://www.endocrineconnections.org DOI: 10.1530/EC-15-0112 
Table 1 Associations between RAS polymorphisms and endometrial cancer risk.

\begin{tabular}{|c|c|c|c|}
\hline Gene & Polymorphism & Genotype & Controls n (\%) \\
\hline \multirow[t]{3}{*}{$A C E$} & rs4291 & AA & $60(39.2)$ \\
\hline & & AT & $70(45.7)$ \\
\hline & & TT & $23(15.0)$ \\
\hline \multirow[t]{3}{*}{$A C E$} & rs4292 & $\mathrm{CC}$ & $24(15.7)$ \\
\hline & & $\mathrm{CT}$ & $68(44.4)$ \\
\hline & & TT & $61(39.9)$ \\
\hline \multirow[t]{3}{*}{$A G T$} & rs699 & AA & $40(30.1)$ \\
\hline & & AG & $54(40.6)$ \\
\hline & & GG & $39(29.3)$ \\
\hline \multirow[t]{3}{*}{ AGTR1 } & rs5186 & AA & $84(54.5)$ \\
\hline & & $A C$ & $58(37.7)$ \\
\hline & & $\mathrm{CC}$ & $12(7.8)$ \\
\hline \multirow[t]{3}{*}{ ATP6AP2 } & rs2968915 & $\mathrm{AA}$ & $112(83.6)$ \\
\hline & & AG & $19(14.2)$ \\
\hline & & GG & $3(2.2)$ \\
\hline
\end{tabular}

\begin{tabular}{c}
\hline Cases $\boldsymbol{n}(\%)$ \\
\hline $65(35.5)$ \\
$90(49.2)$ \\
$28(15.3)$ \\
$27(14.9)$ \\
$88(48.6)$ \\
$66(36.5)$ \\
$78(42.6)$ \\
$83(45.4)$ \\
$22(12.0)$ \\
$72(39.6)$ \\
$82(45.1)$ \\
$28(15.4)$ \\
$151(82.5)$ \\
$28(15.3)$ \\
$4(2.2)$
\end{tabular}

$\chi^{2}$

$P=0.7727$

OR $(95 \% \mathrm{Cl})$
$1.087(0.796-1.485)$

$0.9459(0.6918-1.293)$

0.7501

$P=0.0004$

$0.5394(0.3906-0.7449)$

0.0002

$P=0.02$

$1.671(1.201-2.324)$

0.0023

$P=0.07$

$1.143(0.6692-1.953)$

0.6853

OR, odds ratio; $95 \% \mathrm{Cl}, 95 \%$ confidence interval. Bold values are used to identify the significant differences. rs4292 and rs5186 in women with EC were significantly different between women who had used HRT compared with those who had not used HRT. The TT genotype of rs4291 was more prevalent in the women with EC who used HRT (27.3 vs $11.5 \%$, Fisher's exact $=7.94, P=0.02)$, as was the CC genotype of rs4292 (27.3 vs 10.9\%; Fisher's exact $=8.11, P=0.017$, Fig. 1 and Table 2 ). The prevalence of the CC genotype of rs5186 was also greater in women with EC who used HRT than in women with EC who did not use HRT (27.3 vs $11.6 \%$, Fisher's exact $=8.35$, $P=0.016$, Fig. 1 and Table 2).

\section{Discussion}

Tissue RASs acting through the interaction of Ang II with its type 1 receptor (AGTR1) have been shown to promote angiogenesis, cell proliferation and invasion (17). In particular, Ang II has been shown to stimulate secretion of angiogenic factors and promote cell proliferation in EC cell lines (18). Since drugs that block the AGTR1, such as losartan (19) and telmisartan (20), can inhibit the actions of Ang II, it would logically follow that AGTR1 blockade can inhibit EC cell growth in vitro. In addition, studies with nude mice have shown that in vivo tumour cell growth in a human endometrial adenocarcinoma cell line (HHUA) is inhibited by telmisartan (5). Apart from epidemiological studies implicating tissue RASs in cancer growth and spread, their role in regulating the growth and spread of EC is unknown.

An analysis of data from a larger GWAS study on EC (21) has determined that neither rs699, rs5186 nor the two ACE SNPs (rs4291 and rs4292) were assessed in that study ( $\mathrm{R}$ Scott, personal communication). Interestingly, the ATP6AP2 SNP (rs2968915) was assessed in this GWAS and was significantly associated with EC $(P=0.003)$; this is in contrast to our findings (Table 1). Two SNPs in the ACE gene (rs1800764 and rs4293), which we have not examined in our cohort, were also significantly associated with EC in the GWAS $(P=0.005$ and $P=0.006$, respectively); this may warrant further investigation.

Table 2 Associations between RAS polymorphisms and risk factors for endometrial cancer in women with endometrial cancer.

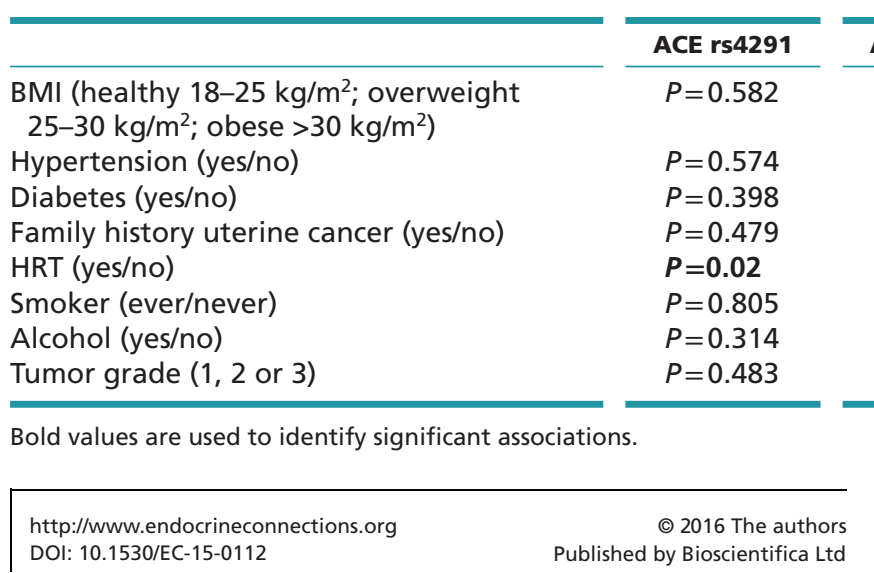

\begin{aligned} ACE s4292 \\ \hline$P=0.549 \\ P=0.677 \\ P=0.36 \\ P=0.51 \\ P=0.017 \\ P=0.897 \\ P=0.228 \\ P=0.336\end{aligned}$

\begin{tabular}{c} 
AGT rs699 \\
\hline$P=0.678$ \\
$P=0.934$ \\
$P=0.306$ \\
$P=0.590$ \\
$P=0.463$ \\
$P=0.087$ \\
$P=0.652$ \\
$P=0.582$
\end{tabular}

\begin{tabular}{c} 
AGTR1 rs5186 \\
\hline$P=0.462$ \\
$P=0.958$ \\
$P=0.525$ \\
$P=0.241$ \\
$P=0.016$ \\
$P=0.651$ \\
$P=0.058$ \\
$P=0.643$
\end{tabular}

\begin{tabular}{c} 
ATP6AP2 rs2968915 \\
\hline$P=0.551$ \\
$P=0.883$ \\
$P=0.354$ \\
$P=1.000$ \\
$P=0.596$ \\
$P=0.849$ \\
$P=0.137$ \\
$P=0.408$
\end{tabular}

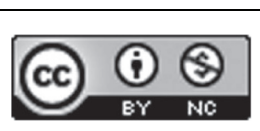

This work is licensed under a Creative Commons Attribution-NonCommercial 4.0 International License. 
A rs4291

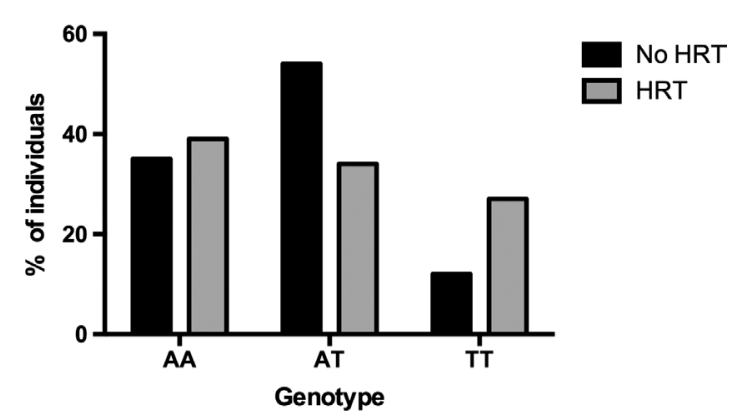

B

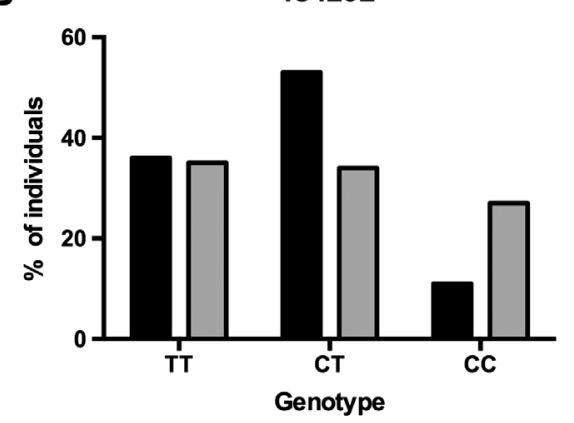

C

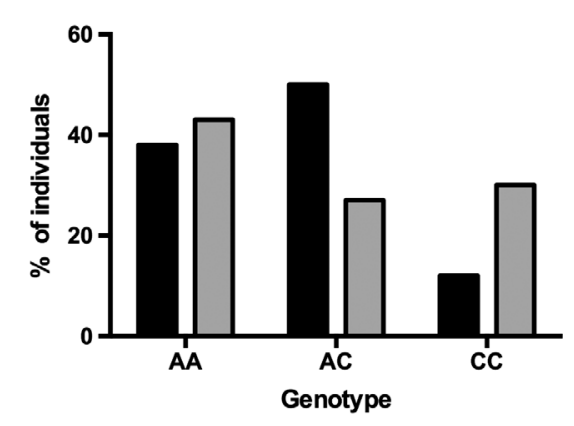

\section{Figure 1}

The distribution of the genotypes of rs4291 (A), rs4292 (B) and rs5186 (C) between women with EC who had no history of using hormone replacement therapy (No HRT, black bars) and those who had a history of using hormone replacement therapy (HRT, grey bars). The genotype distribution for (A) rs4291 was $n=48 / 75 / 16$ (AA/AT/TT) for No HRT and $n=17 / 12 / 16$ for HRT; rs4292: $n=49 / 73 / 15$ (TT/CT/CC) for No HRT, $n=17 / 12 / 15$ for HRT; (C) rs5186: $n=53 / 69 / 16$ (TT/CT/CC) for No HRT and $n=19 / 13 / 12$ for HRT.

We have shown for the first time that a SNP in the AGTR1 gene (rs5186), which is known to be associated with overexpression of the AGTR1, is more prevalent in women with EC. The CC genotype is associated with an increased expression of AGTR1, with a 2.4 times higher chance of hypertension $(22,23)$. This polymorphism is also associated with an increased risk of renal cell carcinoma (24). The increase in AGTR1 protein in CC homozygotes may be related to the lack of complementarity of the $\mathrm{C}$ allele with miR-155, which can interact with the A allele (25).

We also showed that the rs699 SNP in the AGT gene was decreased in prevalence in women with EC. The GG genotype is associated with a $10-20 \%$ increase in plasma AGT levels and has been implicated in hypertension (26). AGT is expressed in human decidua (pregnant endometrium), and in human endometrial stromal cells, expression is stimulated by a 'cocktail' of medroxyprogesterone acetate, estradiol 17B and cAMP (9). Plasma AGT is mainly produced by the liver, but there is evidence that adipose tissue AGT enters the circulation (27).

AGT is a large molecule of 452 amino acids. It is the specific substrate for renin that cleaves 10 amino acids from AGT to form Ang I, the precursor to Ang II and the major biologically active peptide of the RAS. The remaining molecule is about $98 \%$ of the original AGT and is known as des(Ang I)AGT. Intact AGT and des(Ang I)AGT have structures like serine proteinase inhibitors (serpins) but have no inhibitory activity. Other members of the serpin family that have no inhibitory activity include maspin (SERPINB5, a putative anti-tumour agent), which blocks angiogenesis (28).

Celerier and coworkers showed that AGT and des(Ang I)AGT, like SERPINB5, both inhibit angiogenesis, blocking VEGFA-stimulated proliferation, endothelial cell migration and endothelial tube formation (3). They postulate that AGT and in particular des(Ang I)AGT, through their antiangiogenic actions, oppose the pro-angiogenic arm of the RAS (i.e. Ang II acting via its AGTR1). The clearance of des(Ang I)AGT is much slower than that of Ang II, so its actions might last longer.

It is of great interest that we have found, in women with EC, a change in the prevalence of two SNPs that could regulate angiogenesis and tumour spread through their activities within the endometrial RAS. The increased prevalence of the CC polymorphism in AGTR1 rs5186 in women with EC could result in greater stimulation of the pro-angiogenic arm, that is, Ang II-AGTR1 through increased expression of AGTR1, whereas the reduced prevalence of the GG genotype in AGT rs699 in the same population results in a reduction in anti-angiogenic capacity, due to lower AGT and lower des(Ang I)AGT levels.

In both the control and the EC population, the two ACE SNPs, rs4291 and rs4292, were in complete linkage disequilibrium. In EC women alone, rs4291 but not rs4292 appeared to be linked to rs5186, in that the TT genotype

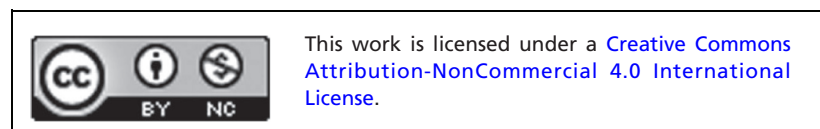


appeared in $35.7 \%$ of women with the CC genotype of rs5186. Although there was no evidence of increased prevalence of either of the ACE polymorphisms in women with EC, rs4291 is associated with higher serum ACE activity (29), and its linkage with rs5186 might provide further evidence of a genetically driven activation of the RAS pathway in women with EC.

When we looked at the biophysical profile of the women who had EC, we found that 50\% were obese, were hypertensive and drank alcohol. Obesity is a wellknown risk factor for EC and the increasing prevalence of EC has been attributed to the rising level of obesity in the community. Thus, it was not perhaps surprising that $50 \%$ of women with EC were obese. The association with obesity is complex, and a recent study suggests that the association between EC and adiposity is not directly associated with the genetic risk of excess BMI but is due to obesity itself, and genes that predispose to EC (30). There were no differences in the prevalence of the SNPs we studied in women with EC who were obese, drank alcohol, or were hypertensive. HRT was the only factor in women with EC that did show a difference in the distribution of SNP genotypes. Women who had EC and a history of using HRT had a higher prevalence of the rs5186, which we have shown to be more prevalent in women with EC. Two other SNPs (rs4291 and rs4292), which are associated with an upregulation of the activity of the RAS, were also more prevalent in women with EC who had a history of using HRT. HRT is a known risk factor for EC (31). The higher prevalence of three RAS SNPs in women with EC and who have taken HRT might suggest that their presence in these women amplifies the carcinogenic potential of HRT.

Postmenopausal therapy with oestrogens alone predisposes to EC (IARC), which is sustained for up to 15 years after use (31). We do not know the nature or duration of HRT use in our cohort of women with EC. The use of oestrogen-progestin combination as postmenopausal therapy is associated with reduced risk of EC if the progestin is administered continuously or an increased risk (albeit reduced relative to oestrogen alone therapy) if progestin is administered cyclically for less than 10 days (IARC, (31)). The effects of body weight and oestrogen use are not multiplicative (see IARC).

As stated previously, obesity is however a major risk factor for EC. For every $5 \mathrm{~kg} / \mathrm{m}^{2}$ increase in BMI, the overall risk ratio is 1.6 (95\% CI 1.58-1.60, P<0.0001) (31). Adipose tissue aromatises androgen precursors leading to high oestrogen levels (32). There was a strong association between hypertension and obesity in our cohort of women with EC (63\% of hypertensive women with EC were obese). This association is well described and may involve the RAS through compression of the kidneys by fat or through sympathetic stimulation of the kidneys. Adipose tissue also has its own RAS and secretes leptin (LEP), which causes increased plasma Ang II levels (33). LEP levels are increased in obese women with EC (34) and related to their greater BMI (35). In vitro, LEP secreted from obese adipose tissue stromal cells enhanced growth of $\mathrm{ER}^{+}$ breast cancer cells (36). LEP also stimulates angiogenesis $(37,38)$. Therefore, in obese women, not only are there higher oestrogen levels but there are also higher levels of LEP which is tumourigenic both through its direct actions and possibly by its ability to stimulate the RAS, although it is only one of a number of pathways through which Ang II levels are increased in obesity.

We suggest that the high prevalence of rs5186, which is associated with overexpression of the AGTR1, its linkage with the ACE activity promoting SNP rs4291 in women with EC and the lower prevalence of rs699, which lowers the levels of the anti-angiogenic AGT and hence des(Ang I)AGT, provide a genetic background that enhances the pro-inflammatory, mitogenic and angiogenic actions of high levels of LEP and Ang II. This could partly contribute to the well-known association between obesity and EC seen in other studies.

\section{Declaration of interest}

The authors declare that there is no conflict of interest that could be perceived as prejudicing the impartiality of the research reported.

\section{Funding}

This work was supported by a grant from the John Hunter Charitable Trust.

\section{Author contribution statement}

Lumbers, Scott, Blackwell and Pringle designed experiments; Pringle carried out experiments; Lumbers and Pringle analysed data; Wang and Delforce drafted the manuscript; Ashton carried out DNA extraction and provided patient data; and Proietto and Otton provided patient samples. All authors were involved in the editing and/or writing of this manuscript and provided critical intellectual comments.

\section{References}

1 Bokhman JV. Two pathogenetic types of endometrial carcinoma. Gynecologic Oncology 198315 10-17. (doi:10.1016/00908258(83)90111-7)

2 Gorzelniak K, Engeli S, Janke J, Luft FC \& Sharma AM. Hormonal regulation of the human adipose-tissue reninangiotensin system: relationship to obesity and hypertension. Journal of Hypertension 200220 965-973. (doi:10.1097/00004872200205000-00032)

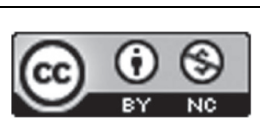

This work is licensed under a Creative Commons Attribution-NonCommercial 4.0 International License. 
3 Celerier J, Cruz A, Lamande N, Gasc JM \& Corvol P. Angiotensinogen and its cleaved derivatives inhibit angiogenesis. Hypertension 200239 224-228. (doi:10.1161/hy0202.103441)

4 Herr D, Bekes I \& Wulff C. Local Renin-Angiotensin system in the reproductive system. Frontiers in Endocrinology 20134150. (doi:10.3389/fendo.2013.00150)

5 Koyama N, Nishida Y, Ishii T, Yoshida T, Furukawa Y \& Narahara H. Telmisartan induces growth inhibition, DNA double-strand breaks and apoptosis in human endometrial cancer cells. PLoS ONE 20149 e93050. (doi:10.1371/journal.pone.0093050)

6 Sanchez-Lopez E, Lopez AF, Esteban V, Yague S, Egido J, Ruiz-Ortega M \& Alvarez-Arroyo MV. Angiotensin II regulates vascular endothelial growth factor via hypoxia-inducible factor-1alpha induction and redox mechanisms in the kidney. Antioxidants and Redox Signaling 20057 1275-1284. (doi:10.1089/ars.2005.7.1275)

7 Nguyen G, Delarue F, Burckle C, Bouzhir L, Giller T \& Sraer JD. Pivotal role of the renin/prorenin receptor in angiotensin II production and cellular responses to renin. Journal of Clinical Investigation $2002 \mathbf{1 0 9}$ 1417-1427. (doi:10.1172/JCI14276)

8 Li XF \& Ahmed A. Compartmentalization and cyclic variation of immunoreactivity of renin and angiotensin converting enzyme in human endometrium throughout the menstrual cycle. Human Reproduction 199712 2804-2809. (doi:10.1093/humrep/12.12.2804)

9 Lumbers ER, Wang Y, Delforce SJ, Corbisier de Meaultsart C, Logan PC, Mitchell MD \& Pringle KG. Decidualisation of human endometrial stromal cells is associated with increased expression and secretion of prorenin. Reproductive Biology and Endocrinology 201513 129. (doi:10.1186/s12958-015-0127-8)

10 Deshayes F \& Nahmias C. Angiotensin receptors: a new role in cancer? Trends in Endocrinology \& Metabolism 200516 293-299. (doi:10.1016/j.tem.2005.07.009)

11 Lever AF, Hole DJ, Gillis CR, McCallum IR, McInnes GT, MacKinnon PL, Meredith PA, Murray LS, Reid JL \& Robertson JW. Do inhibitors of angiotensin-I-converting enzyme protect against risk of cancer? Lancet 1998352 179-184. (doi:10.1016/S01406736(98)03228-0)

12 Ronquist G, Rodriguez LA, Ruigomez A, Johansson S, Wallander MA, Frithz G \& Svardsudd K. Association between captopril, other antihypertensive drugs and risk of prostate cancer. Prostate 200458 50-56. (doi:10.1002/pros.10294)

13 Piastowska-Ciesielska AW, Płuciennik E, Wójcik-Krowiranda K, Bieńkiewicz A, Bednarek A \& Ochędalski T. Analysis of the expression of angiotensin II type 1 receptor and VEGF in endometrial adenocarcinoma with different clinicopathological characteristics. Tumor Biology 201233 767-774. (doi:10.1007/s13277-011-0292-0)

14 Miller S, Dykes D \& Polesky H. A simple salting out procedure for extracting DNA from human nucleated cells. Nucleic Acids Research 198816 1215. (doi:10.1093/nar/16.3.1215)

15 Scott RJ, McPhillips M, Meldrum CJ, Fitzgerald PE, Adams K, Spigelman AD, du Sart D, Tucker K \& Kirk J. Hereditary nonpolyposis colorectal cancer in 95 families: differences and similarities between mutation-positive and mutation-negative kindreds. American Journal of Human Genetics 200168 118-127. (doi:10.1086/316942)

16 Gaunt TR, Rodriguez S \& Day IN. Cubic exact solutions for the estimation of pairwise haplotype frequencies: implications for linkage disequilibrium analyses and a web tool 'CubeX'. BMC Bioinformatics 20078 428. (doi:10.1186/1471-2105-8-428)

17 George AJ, Thomas WG \& Hannan RD. The renin-angiotensin system and cancer: old dog, new tricks. Nature Reviews Cancer 201010 745-759. (doi:10.1038/nrc2945)

18 Watanabe Y, Shibata K, Kikkawa F, Kajiyama H, Ino K, Hattori A, Tsujimoto M \& Mizutani S. Adipocyte-derived leucine aminopeptidase suppresses angiogenesis in human endometrial carcinoma via Renin-Angiotensin system. Clinical Cancer Research 20039 6497-6503.
19 Wong PC, Price WA, Chiu AT, Duncia JV, Carini DJ, Wexler RR, Johnson AL \& Timmermans PB. Nonpeptide angiotensin II receptor antagonists. VIII. Characterization of functional antagonism displayed by DuP 753, an orally active antihypertensive agent. Journal of Pharmacology and Experimental Therapeutics 1990252 719-725.

20 Wienen W, Hauel N, Van Meel JC, Narr B, Ries U \& Entzeroth M. Pharmacological characterization of the novel nonpeptide angiotensin II receptor antagonist, BIBR 277. British Journal of Pharmacology 1993110 245-252. (doi:10.1111/j.1476-5381.1993. tb13800.x)

21 Spurdle AB, Thompson DJ, Ahmed S, Ferguson K, Healey CS, O'Mara T, Walker LC, Montgomery SB, Dermitzakis ET, Australian National Endometrial Cancer Study Group, et al. Genome-wide association study identifies a common variant associated with risk of endometrial cancer. Nature Genetics 201143 451-454. (doi:10.1038/ ng.812)

22 Chandra S, Narang R, Sreenivas V, Bhatia J, Saluja D \& Srivastava K. Association of angiotensin II type 1 receptor (A1166C) gene polymorphism and its increased expression in essential hypertension: a case-control study. PLOS ONE 20149 e101502. (doi:10.1371/journal. pone.0101502)

23 Liu DX, Zhang YQ, Hu B, Zhang J \& Zhao Q. Association of AT1R polymorphism with hypertension risk: an update meta-analysis based on 28,952 subjects. Journal of the Renin-Angiotensin-Aldosterone System 201516 898-909. (doi:10.1177/1470320315584096)

24 Deckers IA, van den Brandt PA, van Engeland M, van Schooten FJ, Godschalk RW, Keszei AP \& Schouten LJ. Polymorphisms in genes of the renin-angiotensin-aldosterone system and renal cell cancer risk: interplay with hypertension and intakes of sodium, potassium and fluid. International Journal of Cancer 2015136 1104-1116. (doi:10.1002/ijc.29060)

25 Ceolotto G, Papparella I, Bortoluzzi A, Strapazzon G, Ragazzo F, Bratti P, Fabricio AS, Squarcina E, Gion M, Palatini P, et al. Interplay between miR-155, AT1R A1166C polymorphism, and AT1R expression in young untreated hypertensives. American Journal of Hypertension 201124 241-246. (doi:10.1038/ajh.2010.211)

26 Jeunemaitre X, Soubrier F, Kotelevtsev YV, Lifton RP, Williams CS, Charru A, Hunt SC, Hopkins PN, Williams RR \& Lalouel J-M. Molecular basis of human hypertension: role of angiotensinogen. Cell 199271 169-180. (doi:10.1016/0092-8674(92)90275-H)

27 Kalupahana NS \& Moustaid-Moussa N. The adipose tissue reninangiotensin system and metabolic disorders: a review of molecular mechanisms. Critical Reviews in Biochemistry and Molecular Biology 201247 379-390. (doi:10.3109/10409238.2012.694843)

28 Zhang M, Volpert O, Shi YH \& Bouck N. Maspin is an angiogenesis inhibitor. Nature Medicine 20006 196-199. (doi:10.1038/72303)

29 Baghai TC, Binder EB, Schule C, Salyakina D, Eser D, Lucae S, Zwanzger P, Haberger C, Zill P, Ising M, et al. Polymorphisms in the angiotensin-converting enzyme gene are associated with unipolar depression, ACE activity and hypercortisolism. Molecular Psychiatry $\mathbf{1 1}$ 2006 1003-1015. (doi:10.1038/sj.mp.4001884)

30 Prescott J, Setiawan VW, Wentzensen N, Schumacher F, Yu H, Delahanty R, Bernstein L, Chanock SJ, Chen C, Cook LS, et al. Body mass index genetic risk score and endometrial cancer risk. PLoS ONE 201510 e0143256. (doi:10.1371/journal.pone.0143256)

31 Crosbie EJ, Zwahlen M, Kitchener HC, Egger M \& Renehan AG. Body mass index, hormone replacement therapy, and endometrial cancer risk: a meta-analysis. Cancer Epidemiology, Biomarkers \& Prevention 201019 3119-3130. (doi:10.1158/1055-9965.EPI-10-0832)

32 Nelson LR \& Bulun SE. Estrogen production and action. Journal of the American Academy of Dermatology 200145 S116-124.

33 Thieme K \& Oliveira-Souza M. Renal hemodynamic and morphological changes after 7 and 28 days of leptin treatment: the participation of angiotensin II via the AT1 receptor. PLOS ONE 2015 10 e0122265. (doi:10.1371/journal.pone.0122265) http://www.endocrineconnections.org

DOI: 10.1530/EC-15-0112
(๔) 2016 The authors Published by Bioscientifica Ltd
This work is licensed under a Creative Commons Attribution-NonCommercial 4.0 International License. 
34 Petridou E, Belechri M, Dessypris N, Koukoulomatis P, Diakomanolis E, Spanos E \& Trichopoulos D. Leptin and body mass index in relation to endometrial cancer risk. Annals of Nutrition and Metabolism 200246 147-151. (doi:10.1159/000063081)

35 Cymbaluk A, Chudecka-Glaz A \& Rzepka-Gorska I. Leptin levels in serum depending on Body Mass Index in patients with endometrial hyperplasia and cancer. European Journal of Obstetrics \& Gynecology and Reproductive Biology 2008136 74-77. (doi:10.1016/j.ejogrb.2006.08.012)

36 Strong AL, Ohlstein JF, Biagas BA, Rhodes LV, Pei DT, Tucker HA, Llamas C, Bowles AC, Dutreil MF, Zhang S, et al. Leptin produced by obese adipose stromal/stem cells enhances proliferation and metastasis of estrogen receptor positive breast cancers. Breast Cancer Research 201517 112. (doi:10.1186/s13058-015-0622-z)

37 Manjunathan R \& Ragunathan M. In ovo administration of human recombinant leptin shows dose dependent angiogenic effect on chicken chorioallantoic membrane. Biological Research 201548 29. (doi:10.1186/s40659-015-0021-z)

38 Tahergorabi Z \& Khazaei M. Leptin and its cardiovascular effects: focus on angiogenesis. Advanced Biomedical Research 2015479. (doi:10.4103/2277-9175.156526)

Received in final form 23 March 2016

Accepted 11 April 2016
This work is licensed under a Creative Commons Attribution-NonCommercial 4.0 International License. 